\title{
Mitos, ritos, identidad y alteridad en un estadio de fútbol
}

\section{Myths, Rites, Identity and Alterity in a Football Stadium}

\author{
Ángel Acuña Delgado ${ }^{1}$ \\ Universidad de Granada/Universidad Autónoma de Chile \\ Guillermo Acuña Gómez² \\ Universidad de Granada
}

\section{RESUMEN}

A partir del trabajo de investigación sobre la cultura de gradas generada en el estadio del Granada Club de Fútbol, desarrollado en el transcurso de tres temporadas futbolísticas (2013-2014, 2014-2015 y 2015-2016), centramos aquí la atención fundamentalmente en aspectos simbólicos del comportamiento de los aficionados para responder a tres objetivos claves: 1 . describir, caracterizar y encontrar sentido a los mitos más destacados entre los seguidores; 2 . hacer lo mismo con los ritos que tienen lugar en el estadio y en torno al encuentro; 3. valorar el efecto que la asistencia al estadio tiene sobre la construcción de la identidad y alteridad de los/as espectadores/as.

Palabras clave: Mitos; Ritos; Identidad; Alteridad; Fútbol; Deporte.

\section{SUMMARY}

Based on research work into stadium culture generated at Granada Football Club, conducted over the course of three football seasons (2013-2014, 2014-2015 and 2015-2016), we focus on symbolic aspects of fan behaviour to achieve three key objectives: 1. to describe, characterise and make sense of the most outstanding myths among followers; 2. to do the same with rites taking place in the stadium and around the meeting; and 3. to evaluate the effect of stadium attendance on the construction of the identity and alterity of spectators.

Key words: Myths; Rites; Identity; Alterity; Football; Sport.

\section{INTRODUCCIÓN}

Desde que comenzaron los estudios sobre el fútbol como deporte espectáculo, son muchos los ángulos desde donde ha sido analizado y uno de ellos es el del simbolismo. El fútbol, el estadio, el propio juego y todo lo que alrededor sucede antes, durante y

\footnotetext{
${ }^{1}$ Correo electrónico: acuna@ugr.es. ORCID iD: http://orcid.org/0000-0002-9218-2838.

${ }^{2}$ Correo electrónico: guilleago@hotmail.com. ORCID iD: http://orcid.org/0000-0001-5332-7099.
} 
después del momento de competición cobran por lo general un sentido ritual y, según algunos, casi religioso, especialmente para ese sector de aficionados a los que llamamos hinchas o fans (por su fanatismo). Vázquez Montalbán (2005: 58) admite en su libro Una Religión en busca de un Dios, que son tantos los símiles y analogías que podemos encontrar en el fútbol, que para el hincha más fiel puede suponer el sustitutivo a las creencias divinas.

Algunas de esas analogías entre fútbol y religión las encontramos en Verdú (1980), quien llama la atención sobre la religiosidad del penitente hincha, la contemplación del jugador como objeto de placer, la variación de los sistemas de juego en correspondencia con las sucesivas coyunturas sociales, o los sueños matriarcales que gobiernan el inconsciente del equipo; interpretando los comportamientos producidos en el estadio como sistemas de comunicación cargados de simbolismo: las funciones curanderas del masajista, la función totémica de las porterías, la función represora y poseedora de la verdad del árbitro, la función fetichista de las bufandas, escudos y banderas como elementos sagrados que no conviene ultrajar, etc. Cachán y Fernández (1998: 3) observan además que en el fútbol "como ceremonia-acontecimiento interviene un tiempo que es el Gran Tiempo (mítico, no cronológico), un espacio que es la escena tribal y una energía que es la libido (ir a muerte: ganar/perder-vida/muerte)". Así como el carácter de mártir que tiene el hincha del equipo, que "acude al estadio a sufrir, encontrando la alegría solo tras el padecimiento" (1998: 13). Como señala González Ponce de León (2009), prácticamente todos los elementos presentes en un partido de fútbol, ya sea dentro del terreno de juego, o fuera de él, cobran un sentido simbólico para los aficionados que, sin ser conscientes de ello, condicionan su comportamiento; véanse así las imágenes fetichistas y totémicas que se encuentran "en los emblemas, escudos, pegatinas, bufandas, muñecos, trofeos de las vitrinas y toda una serie de artículos que se venden en los alrededores de los estadios antes de los partidos" (2009: 9). Las porterías, el balón, el árbitro o el masajista tampoco escapan a los significados simbólicos.

Bromberger (1989: 54) plantea la analogía entre el ritual del partido de fútbol en el estadio y la asistencia a un ritual religioso, en cuanto que existe un lenguaje especial entre los aficionados, reconocimiento de una jerarquía de estatus, idolatría hacia ciertos jugadores, tensión entre el universalismo de la práctica y del espectáculo y el particularismo de lo local, repetibilidad del acontecimiento, y, sobre todo, la trama secuencial del partido y la trascendencia que se le atribuye a gestos y resultados.

El espectáculo de fútbol no explica de dónde venimos ni a donde vamos (como la religión), pero nos habla del mérito individual, de la solidaridad colectiva, de la competencia, del rendimiento, de la clasificación, de las fidelidades y lealtades locales, de las contradicciones existenciales; atributos todos ellos de la vida moderna, vividos de manera ambigua entre el drama y la comedia, la pasión y el mercado, el fervor y el consumo, el ritual y el espectáculo.

El partido de fútbol, expresa Bromberger (1989), al igual que Ramonet (1999) y Fábregas (2001), puede ser considerado con toda propiedad como un "hecho social total", y el ritual por excelencia en la sociedad moderna actual, en el que la colectividad moviliza y teatraliza sus recursos sociales y simbólicos.

González Ponce de León (2009), en consonancia con otros autores, clasifica el evento deportivo de fútbol profesional como un ritual de carácter lúdico enmarcado 
en el tiempo libre. Dávila y Londoño (2003: 127) apuntan que el fútbol ofrece al público la oportunidad y capacidad de compartir, simpatizar, juzgar o atender a una representación lúdica, estética, en definitiva, un juego con el que identificarse. O como señala Bromberger (1989), un crisol excepcional de identificaciones que se modulan en función de una ciudad, una región, un estilo de juego, un tipo de jugadores, acontecimientos históricos, anécdotas ocurridas, etc.

El deporte es uno de los mecanismos de socialización más difundidos en el mundo actual, y no es arbitrario que se busque entender los procesos y procedimientos de identidad social en el mundo investigando los deportes. Precisamente el interés de los científicos por estudiar el fútbol y su contexto, tiene como objeto conocer las funciones sociales que se asignan en cada momento y lugar específico, así como las diversas prácticas que comprenden ese campo. La premisa que subyace a estos estudios es que las funciones sociales que puede cumplir desbordan ampliamente su reconocido carácter lúdico para las multitudes agobiadas por el ritmo de vida contemporáneo.

Mecanismo de socialización, y en consecuencia constructor de identidades (y alteridades), que se inicia en un proceso, a veces autorreflexivo, a veces inconsciente, de vincular el sí mismo (mismidad) a algo o a alguien en qué o en quién creer, para poder decir "yo soy" y, junto con los demás, "nosotros somos"; al mismo tiempo que produce la sensación de distinguirse del otro o de los otros (otredad), que mantienen otras vinculaciones, y de quienes se dice: "él es" o "ellos son". Aunque, como bien indica Guerrero: "La identidad es una construcción dialógica que se edifica en una continua dialéctica relacional entre la identificación y la diferenciación, entre la pertenencia y la diferencia" (Guerrero 2002: 101-102).

Por ser un deporte colectivo de contacto y de competición, el fútbol se ha convertido en "la batalla más seria del mundo" (Bromberger 2007: 123), que condensa y dramatiza, a modo de ilusión realista, los valores cardinales de las sociedades industriales modernas.

Según la visión sociológica de Ferreiro (2003: 58), el fútbol supone un complejo ritual que incluye dos subprocesos: uno ocurre dentro del campo de juego; el otro en las gradas y entre los espectadores. El primero vinculado a una performance con su resultado en función de una serie de reglas; el segundo vincula una performance con un proceso identitario basado en el antagonismo. El fútbol, indica Villena (2003: 26), actúa de arena pública en el proceso de construcción de identidades sociales y culturales de diverso cuño, sean identidades de pertenencia (identidades territoriales-regionales, locales, nacionales, genéricas, generacionales, de clase, etc.) o identidades de rol (hinchas, jugadores). Cada confrontación, dice Bromberger (2011: 8), proporciona a los espectadores un soporte para la simbolización de una faceta (local, profesional, regional, étnica, nacional,...) de su identidad.

En base al trabajo de investigación sobre la cultura de gradas generada en el estadio del Granada Club de Fútbol, desarrollado en el transcurso de tres temporadas futbolísticas (2013-2014, 2014-2015 y 2015-2016), centramos aquí la atención fundamentalmente en aspectos simbólicos del comportamiento de los aficionados para responder a tres objetivos claves: 1. describir, caracterizar y encontrar sentido a los mitos más destacados entre los seguidores; 2. hacer lo mismo con los ritos que tienen lugar en el estadio y en torno al encuentro; 3. valorar el efecto que la asistencia al estadio tiene sobre la construcción de la identidad y alteridad de los/as espectadores/as. 


\section{METODOLOGÍA}

La población con la que estudiamos estuvo formada por todas aquellas personas que, independientemente de su procedencia (lugar de nacimiento, nacionalidad...), sexo, edad, clase social, estatus profesional, y cualquier otro rasgo de su identidad, fueran aficionadas al fútbol y asistieran de manera regular como espectadoras al Nuevo Estadio Los Cármenes, estadio del Granada Club de Fútbol.

La metodología empleada tuvo carácter etnográfico y fue por tanto básicamente cualitativa, de acuerdo a las técnicas de registro empleadas (observación sistemática, conversaciones informales, entrevistas, grupo de discusión, noticias en medios de comunicación, colección fotográfica); aunque el procedimiento cuantitativo (a través de la encuesta) también estuvo presente, enriqueciéndose así el proceso de producción de datos.

La observación científica dentro y en las inmediaciones del estadio fue participante y no participante según el caso, pero siempre estructurada y sistemática en torno a los parámetros de actitudes y comportamientos que fueron objeto de estudio.

Realizamos un total de 31 entrevistas semiestructuradas, que abarcó una muestra significativa de personas caracterizadas en conjunto por su diversidad, como ocurre en el estadio. Obtuvimos testimonios de 27 hombres (87\%) y 4 mujeres (13\%) en correspondencia aproximada a los porcentajes de público según sexo; de entre 14 y 77 años de edad; localizados en los fondos, tribuna, preferencia, palco o esquinas del estadio; trabajadores y empresarios; vinculados al club de distinta forma y con distinto entusiasmo; periodistas deportivos, socios honoríficos, expresidentes del club, jugadora del equipo femenino, peñistas y socios con gran diversidad de perfiles.

Con el propósito de contrastar ideas, actitudes y sentimientos en torno a determinados asuntos de interés, reunimos un grupo de discusión compuesto por seis personas de entre 23 y 32 años de edad, cinco hombres y una mujer, estudiantes en su mayoría y también trabajadores, regulares asistentes todos ellos al estadio del Granada.

Las conversaciones informales y espontáneas que tuvimos con aficionados al fútbol y asiduos asistentes a los partidos, aprovechando ocasionales coyunturas, fueron tenidas en cuenta como un recurso más y registradas en capítulo aparte dentro del diario de campo.

En cuanto a las técnicas audiovisuales, el uso de la grabadora digital magnetofónica, la cámara fotográfica y eventualmente el propio teléfono móvil, ocupó un papel complementario en el registro de entrevistas, sonido ambiente (cánticos, pitos, etc.) e imágenes significativas en distintos momentos del acontecimiento futbolístico. Además de las obtenidas personalmente sumamos para el análisis las conseguidas por internet relacionadas con los encuentros jugados en Los Cármenes.

A fin de obtener una muestra sobre el estado de opinión del público asistente al estadio en relación con el fútbol y el club al que pertenecen, elaboramos un cuestionario que publicamos en foros digitales del GCF (boards5.melodysoft: amigos del granada club de fútbol y forogcf.com), Twitter y en páginas de amigos del GCF en Facebook. En el plazo de dos semanas fue contestado por un total de 120 personas, 99 hombres $(82,4)$ y 21 mujeres $(17,6)$, con una media de edad de 29,3 años (aunque el rango iba desde los 15 a los 64 años de edad); todas ellas ajustadas al perfil solicitado (asistentes regulares al estadio del Granada). 
La lectura de prensa en los diarios Ideal y Granada boy fue una tarea regular durante la temporada 2013-2014, y más esporádica durante las temporadas 2014-2015 y 2015-2016, coincidiendo con partidos de especial importancia por lo que se jugaba. Igualmente permanecimos atentos a las noticias aparecidas a través de internet, y especialmente por medio de redes sociales.

Por otro lado, la revisión documental nos permitió acceder a un buen número de investigaciones relevantes, con las que ilustrar el estado de la cuestión sobre el tema que nos ocupa.

\section{ANÁLISIS Y DISCUSIÓN DE LOS RESULTADOS}

\section{Mitos}

Las creencias en el fútbol, como en cualquier otro orden de la vida, con frecuencia están basadas en mitos o ideaciones de la realidad que ayudan a interpretarla, mitos que afectan a las personas y a las situaciones que estas generan. En lo relativo a las personas, los mitos generados en el estadio Los Cármenes se fundan sobre todo en torno a los jugadores, jugadores destacados por alguna cualidad cuya presencia o cuyas acciones crean una atracción especial por parte de los aficionados. Contar con jugadores destacados sobre los que el público vuelca especialmente su atención es un rasgo común en el fútbol. Los aficionados desean tener en su equipo al menos algún jugador, de los denominados decisivos o estrellas sobre los que desplegar el imaginario colectivo, jugadores que con su manera de actuar en el campo provocan el deleite de quienes lo ven y suponen una esperanza para solucionar situaciones desesperadas.

El Granada C.F., debido a razones presupuestarias, no cuenta con el nivel de jugadores de aquellos otros equipos que mueven grandes cantidades de dinero por temporada, invierten enormes sumas en nuevos fichajes y de los que se dicen que están "plagados de estrellas". Como club modesto (aspirante a clase media, como algún periodista ha dicho) de Primera División ha de ajustarse a sus posibilidades y el público aficionado es consciente de ello. En tal sentido, jugadores que pasarían desapercibidos en ciertos equipos u ocuparían el banquillo de suplentes, son titulares indiscutibles en el Granada e incluso elevados a la categoría de ídolos. Los seguidores de los equipos necesitan de ese tipo de jugadores para llenar su imaginario, para alimentarles la ilusión, y el Granada no se queda atrás elevando a esa categoría a algunos de ellos cada temporada, como podemos apreciar en las conversaciones entre hinchas y en los medios de comunicación:

Iturra es el que más vale porque siempre está corriendo y luchando, como debe ser. (Alejandro, 16 años, 22/10/2014).

Iturra es un jugador ejemplar [...], su esfuerzo y su espíritu de lucha desde que empieza el partido hasta que acaba contagia a los compañeros. (Nicolás, 26 años, 14/01/2015).

Manuel Iturra, consolidado como nuevo ídolo para la afición. Cada partido que pasa se pone más de manifiesto. El centrocampista chileno Manuel Iturra ha tomado la categoría de ídolo para la afición del Granada C.F. El ex futbolista del Málaga C.F. se ha ganado las simpatías de la afición por su entrega y dedicación en los encuentros. De ahí que muchas de sus intervenciones sean aplaudidas por el respetable (Cánovas, Ideal, 31/10/2013). 
También del jugador Diego Mainz en su despedida del Granada C.F. y retirada definitiva del fútbol escuchamos y leemos:

Ha sido un buen capitán y el mejor defensa que hemos tenido en mucho tiempo, daba confianza al portero, influía sobre la distribución del juego, [...] (José II, 61 años, 12/05/2016). A día de hoy es el que mejor representa los valores del deportista, [...] no le echa la culpa al entrenador ni hace grupos, siente los colores y eso se nota (Andrea, 21 años, 25/ 05/2016).

Adiós al último héroe de los ascensos del Granada (Ideal, 25/09/2016).

Claro que con la misma facilidad que un jugador consigue ser un ídolo para los aficionados por su regularidad en las buenas acciones o por la fama que lo envuelve, puede dejar de serlo si el público pierde las expectativas que tenía puesta sobre él; de lo que también la gente y la prensa se hace eco, como vemos:

Benítez era un pedazo de medio centro defensivo, pero se durmió en los laureles, cometió muchos errores [...] ahora la afición no lo quiere (Paco, 77 años).

El gran fallo de elección de Benítez (Dani Benítez) no fue el botellazo a Clos, ni el consumo recreativo de coca a dos días de un partido. La pifia fue caer en la complacencia de su entorno. El héroe admirado se ha convertido en algo que siempre debió evitar: un juguete roto, derrotado por las polémicas, inducido por unos errores a los que le han arrastrado esa corriente amistosa que tanto daño le ha hecho a su carrera (Ideal, 28/03/2014).

Héroes por tanto que van y vienen, aparecen y desaparecen, pero que cumplen su función, sublimando ciertos valores, a veces los del equipo en su conjunto, y dejando proyectar en ellos los anhelos de los aficionados. "Me gustaría parecerme a Rochina por la precisión y la eficacia de su juego", decía Juan Pablo (24 años, 23/05/2016).

En contraposición al héroe tenemos la figura del chivo expiatorio o víctima propiciatoria, la que expía mediante su sacrificio las culpas de todos (Girard 1985). En el fútbol es muy común, como sabemos, encarnada la figura en distintos personajes: unas veces son ciertos jugadores por su apatía o continuos fallos, otras es el árbitro por sus supuestos errores, otras el presidente de la entidad por su política de fichajes, y otras el entrenador por ser el causante de los males del equipo; todo ello bajo el punto de vista de los aficionados. La pitada o abucheo al árbitro, a algún jugador o al equipo en su conjunto al final de un partido, señala a quien se le considera el principal culpable o el culpable de todo, y sobre él o ellos descarga momentáneamente la tensión del público; es algo habitual. Sin embargo, para calmar la frustración crónica de los aficionados por la racha de malos resultados y cambiar el rumbo del equipo, con razón o sin ella es la destitución del entrenador a lo que se está acostumbrado, lo que generalmente provoca un mayor grado de catarsis y expectativas de renovación. “iLucas vete ya!» gritaban al entrenador del Granada tras la derrota con el R.C. Celta de Vigo (02/02/2014). Si el árbitro ocupa el puesto más destacado (no el único) como chivo expiatorio en el espectáculo que supone cada partido, el entrenador lo es cuando el punto de mira se pone sobre el club. Hay entrenadores que se contratan como apagafuegos para salir de situaciones apuradas, y otros que son contratados con proyectos a largo plazo que exige años para que fragüe; pero aun así, si los malos resultados se instalan durante mucho tiempo suele ser el entrenador el primero en salir. En términos crematísticos se oye comentar que es la solución más barata para propiciar cambios, al tratarse de uno solo y no ser el mejor 
pagado; sin embargo, conociendo lo fugaces que son los entrenadores y siendo consciente de las sorpresas que depara este deporte, lo que resulta chocante (y deja de ser barato) es que sean fichados por varias temporadas, cuando a lo largo de una pueden pasar a veces dos o tres a hacerse cargo de la plantilla. Por el Granada C.F. desde la temporada 2011-2012 hasta la 2016-2017 han pasado un total de 11 entrenadores, solo una de las temporadas empezó y acabó con el mismo entrenador, el granadino Lucas Alcaraz (2013-2014). Abel Resino ha llegado a repetir en estos cinco años dos etapas diferentes, y en la temporada 2014-2015 pasaron por el banquillo hasta cuatro entrenadores diferentes (Joaquín Caparrós, Joseba Aguado, Abel Resino y José Sandoval). El público necesita tener en su equipo héroes que les transmita ilusión, pero también chivos expiatorios donde proyectar su ira cuando las cosas no van bien, para que con su expulsión la ilusión, que no puede faltar, vuelva a ser renovada. La apuesta y adhesión incondicional hacia un entrenador o hacia un jugador en un principio no es poco frecuente que vaya seguida, pasado un tiempo, de su linchamiento verbal, indicadores que nos muestra la imagen de un deporte y un público movido por fuertes pasiones.

Además de los héroes y los villanos (víctimas propiciatorias), el aparato mitológico en el fútbol se alimenta de la terminología empleada para describir personajes y situaciones. El discurso social y mediático generado en torno al fútbol, o más cabría hablar de los discursos generados en torno a este deporte, poseen esquemas lingüísticos compuestos por léxicos cargados de metáforas y repletos de connotaciones que nos acercan a distintos ámbitos, entre los que destacan el sagrado y en especial el guerrero; ámbitos estos en el que los usuarios (aficionados) de manera inconsciente construyen sus respectivas representaciones.

Como consideración de carácter general en la que entra a formar parte el caso granadino, cabe decir que son los medios de comunicación los principales creadores y difusores de las retóricas del fútbol. Las metáforas, comparaciones, hipérboles, abundan para expresar emociones o describir situaciones por parte de los comentaristas de radio, prensa o televisión: "los seguidores del Granada explotan de júbilo en las gradas con el gol", "el terreno de juego ha quedado como un campo de patatas tras el encuentro", "el público está rabioso por la derrota", son comentarios que podemos escuchar a veces, para significar que los seguidores se alegraron, el césped quedó levantado, o el público se enfadó. Pero con diferencia, los códigos simbólicos empleados con más frecuencia por los periodistas deportivos son aquellos que aluden al fútbol como "un rito guerrero, es decir, un "duelo" entre iguales" (Cáceres 2011: 58). El espectáculo generado por un deporte colectivo, de contacto y muy imaginativo, es narrado en muchas fases de su desarrollo, por analogía con el lenguaje empleado, como si de un acontecimiento bélico se tratara. Alguien dijo en cierta ocasión y muchos repitieron más tarde que "el fútbol es un sustituto de la guerra"; la metáfora es muy conocida y, en efecto, la analogía lingüística entre ambos extremos es patente por lo que escuchamos: «en el penalti fusiló al portero" (golpeó con fuerza el balón); "envió un cañonazo a portería" o "un misil" (el balón fue con mucha velocidad); "el Granada cuenta en sus filas con..." (referencia a la alineación), "la escuadra granadina" (el equipo); "el equipo está lanzado a la carga" (ataca con decisión e intensidad); "entran por el flanco más vulnerable" (por la zona más fácil o desprotegida); "colocado en posición de tiro" (preparado para golpear el balón a portería); "se bate en retirada" (optar 
por una actitud defensiva); "el capitán del equipo" (jugador que lo representa); "zona de peligro" (área delante de la portería); "remató de cabeza" (golpeó el balón con la cabeza); "tienen problemas en la retaguardia" (problemas defensivos); "milita en Primera División" (forma parte de esa Liga).

En efecto, todo este lenguaje es reproducido de manera espontánea y natural por muchos aficionados a quienes les escuchamos hablar en sus conversaciones futbolísticas de: contienda, lanzar un misil, un cañonazo a portería o militar en tal o cual equipo.

Como afirma Galeano (1995) el léxico bélico en el fútbol no es casual sino que su sistematicidad permite comprender determinados aspectos de ese deporte en términos de batalla. Sistema conceptual que condiciona la manera de pensar y actuar. Como expresara Lakoff y Johnson (1998: 40): "la esencia de la metáfora es entender y experimentar un tipo de cosa en términos de otra". Metáforas, expresiones en sentido figurado (no literal), importantes de tener en cuenta en cualquier análisis semántico al contener, más allá de su significado lexical, una referencia sobre aquello que designa y una buena carga ideológica y social.

Los comentaristas radiofónicos al retransmitir un partido, al igual que muchos aficionados, emplean con frecuencia términos como: disparo, proyectil, atacante, patea, pega fuerte, enemigo, falta de castigo, combate, contienda, duelo, desafio, tiro, disparo, artillero, barrera defensiva, paliza, contraataque, ofensiva, acomete, retirarse, rendirse, victoria, derrota, etc. Palabras todas ellas fáciles de entender porque forman parte de la comunidad de habla, pero asociadas a un sistema conceptual en donde tales términos son igualmente empleados para describir situaciones bélicas. En consecuencia, las representaciones sociales (Moscovici 1979 [1961]; Ibáñez 1988; Mora 2002) formadas en estos casos entre los seguidores de un equipo de fútbol, como fruto de múltiples interacciones y procesos de intercambio, en especial las que se producen entre los más fanáticos, es fácil que conciban un partido en clave de combate, es decir, que contemplen, piensen (interpreten), sientan (expresen) y actúen (comporten) en un partido de manera parecida a como si de un combate se tratara.

En efecto, como planteaban Lakoff y Johnson (1998), los conceptos "guerra" y "fútbol", dejando al margen las consecuencias derivadas de cada uno de ellos, poseen estructuras semejantes: dos grupos que se enfrentan o compiten; como condición inicial cada grupo ocupa su propio territorio; al principio un grupo comienza atacando; los dos grupos tienen por objetivo conseguir la victoria; estrategias de ataque, defensa, contraataque, etc.; el ataque de uno produce la defensa del otro y el contraataque; al final uno gana y otro pierde o ambos empatan; los resultados finales tienen consecuencia para la posición que ocupa cada cual. Además, las metáforas empleadas, tanto las orientativas como las estructurales, poseen analogías vinculantes. Dentro de las primeras: el triunfo ocupa la posición de arriba y la derrota la de abajo; ascender es bueno y descender malo. Y dentro de las segundas: el fútbol es una contienda: pelea, lucha, competencia, disputa; el balón es un proyectil: bala, cohete, granada, misil, obús, etc.; los jugadores son guerreros: una escuadra, soldados, el equipo; los contrarios son enemigos: oponentes, contrincantes.

La gran diferencia está obviamente en que el fútbol no exige derramamiento de sangre para ganar, la victoria se mide en goles. En tal sentido, conviene precisar que el público granadinista, como otros muchos públicos del fútbol, manifiesta ese tipo de lenguaje y establece también esas analogías, pero consciente de que se trata de 
un deporte de competición no se deja llevar por el significado literal de los términos empleados, quedando tan solo en una manera de hablar y de entender el espectáculo que contempla. Lo cual no es poco, ya que su normalización entre los espectadores, hace que se habitúe y consienta igualmente la violencia verbal y gestual que aparece como constante en las gradas.

Los insultos son una constante y a nivel simbólico se ven muchos cortes de manga por donde yo veo el partido (Ramón, 54 años, 19/05/2016).

Otro amplio ámbito del que se sustrae un buen número de términos y con el que el fútbol mantiene vinculación es el religioso y por extensión sagrado. De los comentaristas deportivos que retransmiten partidos en Los Cármenes, o en cualquier otro estadio, haciéndose eco del ambiente que se vive en el lugar, es fácil escuchar frases como: "la parroquia granadinista" (referida a sus hinchas); "fieles seguidores" (leales); "el escudo es sagrado para ellos" (intocable, esencial); "no pierden la fe" (creencia incondicional); "aún se puede producir el milagro" (la sorpresa de conseguir algo muy difícil); "falta un minuto para alcanzar la gloria" (para que termine el partido con victoria). Metáforas que igualmente producen representaciones sociales que condicionan y orientan las maneras de pensar, sentir y actuar. Si bien el léxico belicista es básicamente utilizado para describir la estructura y dinámica del fútbol, de la actividad deportiva que tiene lugar sobre el terreno de juego, aunque también comportamientos que acontecen en las gradas; el léxico religioso es sobre todo empleado para describir las actitudes y comportamientos de los seguidores que contemplan el espectáculo, y en menor medida lo que ocurre sobre el césped. Analogías que marcan la práctica y el espectáculo del fútbol con connotaciones bélicas y sagradas, las cuales conducen a adoptar una mirada en tales sentidos. Lo bélico lo acabamos de comentar. Lo sagrado está igualmente presente en la medida que el fútbol se vivencie como algo imprescindible sin lo que los aficionados no pueden pasar, esencial para llenar sus vidas y para que ésta cobre mayor sentido. El hecho de que dentro del estadio aparezca un personaje, ya muy popular, disfrazado de Sumo Pontífice, "el Papa del Granada", bendiciendo a los seguidores y al club con sus gestos, no es más que anecdótico, que entendido en clave de humor amplía el espectáculo a la grada; sin embargo, las muestras de afecto, de cariño, de fidelidad, y el culto que los aficionados muestran por su equipo, como símbolo totémico, sí que demuestran esa dimensión sagrada: "Siempre hago una cosa, la noche de antes pongo la camiseta y la bandera encima de la cama y beso el escudo", nos decía Mario (15 años, 18/05/2016).

El honor, al que también se hacen continuas alusiones implícita o explícitamente como valor principal que es preciso mantener siempre, aunque se pierdan los partidos, se encontraría impregnado de ambos aspectos: del espíritu combativo o guerrero, y de la fe y lealtad al equipo. Así lo apreciamos en numerosas conversaciones informales con expresiones como: "aunque bajemos de nuevo a segunda hay que mantener la cabeza siempre alta"; "quienes aceptan sobornos o primas para dejarse ganar por intereses de otros no tienen vergüenza, el club ha de estar por encima de todo"; "perder partidos es entendible porque no tenemos el nivel de otros equipos, lo que no se puede entender es que perdamos nuestro espíritu de lucha"; "es un honor pertenecer a este club". También en el himno se dice: "[...] benditas las victorias, que ganaste con honor". 
RITOS

El fútbol, como práctica deportiva y fenómeno social conlleva una gran carga simbólica y ritual en su lógica interna y en su manifestación externa, siendo el estadio un lugar privilegiado para su puesta en escena. Lugar que enlazado con el tiempo produce acontecimientos (partidos) marcados por el espectáculo y la competición, el encuentro y la socialización; lugar de trabajo para unos y de esparcimiento y diversión para otros, tópico y heterotópico (Foucault 1976) al mismo tiempo según sus usuarios; con memoria y lleno de recuerdos en cualquier caso.

Tanto dentro como fuera de él, los rituales abundan, sobre todo los que tienen carácter confirmatorio, de confraternización, de solidaridad o de intensificación (Harris 1984; Geertz 1987 [1973]; Turner 1988), destinados a reforzar el espíritu de grupo y el sentido de pertenencia de diferentes modos: los cánticos entonados por los aficionados de uno u otro equipo con la pretensión de animar a sus jugadores, acompañados de gestos como mantener las bufandas estiradas y sostenidas en alto con los brazos estirados, generan una especie de espíritu colectivo que fortalece la unidad de acción en la idea de estar todos a una, proyectando los mismos deseos de apoyo a su equipo $^{3}$. Los líderes de los grupos de animación portan un megáfono para que se sigan sus cánticos. Las llamadas entre sectores del estadio para que saluden o boten, y, sobre todo, la ola, vincula no obstante a todos los espectadores e independientemente de la adhesión a uno u otro club, todos están invitados a participar de un gesto (levantarse del asiento y elevar los dos brazos al tiempo cuando toque el turno) que proporciona un aire alegre, distendido al espectáculo, al tiempo que pacífico y festivo. Más allá de las diferencias o preferencias por unos u otros colores y de las tensiones derivadas de la competición deportiva, un simple gesto como este aúna e iguala a todos como aficionados en comunión y hace valer por encima de todo el gusto o fruición que provoca la actividad que contemplan. De otro modo, la costumbre de guardar un minuto de silencio antes de comenzar el partido, con motivo de la muerte de algún miembro de la entidad, de alguna personalidad ajena al club especialmente estimada, sobre todo si fue futbolista, o por las consecuencias sufridas ante algún atentado terrorista, accidente multitudinario o catástrofe natural, acalla a todos de manera sobrecogedora y, en un ambiente competitivo y cargado de pasión, se ofrece una muestra de respeto o reconocimiento hacia el o los protagonistas y da lugar o invita a reflexionar, aunque sea por un instante, sobre la vulnerabilidad del ser humano.

No hay que olvidar, sin embargo, que la lógica del fútbol y en especial el practicado a nivel profesional, hace valer sobremanera el hecho de ganar o perder; incluso el empate es percibido como victoria o como derrota, en positivo o negativo, según qué casos y situaciones. Por tal motivo, junto a los rituales de solidaridad e intensificación orientados a favorecer un resultado positivo, que son los que más abundan por ser lo que todos persiguen; hay que considerar los rituales de aflicción (Turner 1988) dirigidos a hacer soportables los acontecimientos desagradables, las derrotas en

\footnotetext{
3 "Siempre voy uniformado, llevo la camiseta y la bufanda, en invierno sudadera y gorro, o sea que todo del Graná" (F.․ Javier, 55 años, 4/05/2016).

"Camiseta y bufanda siempre, después siempre mi padre y yo llevamos una pancarta sobre algún tema de actualidad de esa semana" (José Antonio, 22 años, 17/05/2016).
} 
este caso, para restaurar el ánimo en el equipo y entre los seguidores. Las pitadas o abucheos colectivos funcionan como ejercicio catártico para liberar el enfado acumulado en el público; así como el cambio de entrenador o el fichaje de algún jugador nuevo, realizado con el propósito de compensar las carencias del equipo y devolver la ilusión a los seguidores. El público de Los Cármenes vitoreaba en numerosas ocasiones el nombre de Ighalo, habitual suplente, como solución a los problemas deportivos del equipo en determinadas situaciones de juego.

Entendido el día del partido como un ritual en su conjunto, por ser un hecho repetido semana tras semana, con alto componente expresivo y comunicativo, sujeto a pautas que seguir, y con gran carga simbólica en los elementos que contiene; cada cual participa de él a su manera: unos reuniéndose previamente con su peña para asistir todos juntos como grupo de animación; otros acompañados por personas muy allegadas, amigas o familiares; otros yendo en solitario. El atuendo alusivo al equipo con que cada cual se viste en casa; el recibimiento de los jugadores al entrar en bus al estadio; las cervezas tomadas en los bares próximos antes de entrar al recinto; el hecho de entrar con tiempo suficiente para ver el calentamiento de los jugadores; los cánticos de animación, la ola, la entonada del himno del club al inicio del tiempo de descanso; las pitadas de descontento; las declaraciones públicas ante los medios de comunicación una vez acabado el encuentro; junto con la gran cantidad de comportamientos individuales que forman parte de la costumbre, del "hábitus", en palabras de Bourdieu (1991 [1980], con que cada persona asiste regularmente a los partidos, dotan al ritual generado por los espectadores de gran densidad simbólica (Sperber 1988), tanto antes, durante y después de celebrado el acontecimiento. Simbolismo que se vuelve aún más complejo al unirse a él todo lo que se desprende de la competición deportiva, entendida también como un ritual en sí misma.

Es muy frecuente ver por todo el estadio pancartas de apoyo a los jugadores, relacionadas con temas de actualidad deportiva, especialmente entre los niños. Más aún es portar la bufanda del equipo al estadio, levantarla durante la entonación del himno, hondearla al viento con los goles que marque, e incluso hacer intercambios con el equipo rival, tal y como se hizo con la Federación de Peñas del Málaga C.F. (8/04/ 2016). Los grupos de animación elaboran tifos (pancartas gigantes) para que sean vistos en los momentos previos al partido a fin de crear ambiente y motivar así a los jugadores, como el que se realizó en el partido ante la U.D. Las Palmas (30/04/2016); y también forman mosaicos organizados por el club para dar colorido al estadio, como el que se pudo ver con el F.C. Barcelona (14/05/2016).

Símbolos todos ellos que en mayor o menor grado ejercen una función oréctica, en la medida que expresan pulsiones, anhelos, deseos profundos y logran hacer eficaz el ritual del que forman parte por su capacidad para hacer sentir y mover a la acción. Como decía Turner (1988: 59-60), los símbolos se hallan "cargados de una fuerza que brota de fuentes desconocidas y que son capaces de actuar sobre las personas y sobre los grupos que entran en contacto con ellos".

Por otro lado, también encontramos rituales que en cierto modo poseen un carácter transformatorio (Van Gennep 2008 [1960]) en quienes lo protagonizan: en el ámbito del equipo y por extensión del club, cabría mencionar el llamativo acto de presentación de los nuevos fichajes ante los micrófonos de los medios de comunicación $\mathrm{y}$ ante los seguidores dentro del estadio; acto presentado y presidido por el presiden- 
te de la entidad ante la atenta mirada de cientos o tal vez miles de aficionados que acuden a las gradas para darle la bienvenida al jugador, sobre todo si viene considerado como una estrella para reforzar al equipo; acto por el que el jugador recién fichado, tras firmar el contrato con el club, comparece ante el público, su público, dando unas pataditas al balón y dirigiéndole unas breves palabras, sustantivando así su nuevo estatus dentro de la plantilla del equipo, ante el reconocimiento y aceptación social de los aficionados. La historia de los jugadores recién fichados queda marcada con un rito de paso en el nuevo espacio escénico que han de ocupar; y para los espectadores, como expresa Bromberger (2010), cada temporada comienza un nuevo ciclo y despierta expectativas socializadoras en las gradas.

Toda persona que adquiere un puesto o cargo de responsabilidad en el club pasa por su correspondiente ritual de paso, ya sea jugador, técnico o directivo, que se hace más o menos público en función de la relevancia que tenga o se le quiera dar. La categoría de hincha, seguidor o aficionado del club, no cuenta sin embargo con un acto puntual claramente definido en donde se pase de no serlo a serlo. Los aficionados lo son por distintos motivos (tradición familiar, vinculación con la ciudad, influencia de amigos, etc.) y a partir de distintos momentos (desde que se nace inducido por el padre, o a partir de cierta edad, normalmente desde muy joven). Llegar a ser socio (abonado) del club es un signo distintivo de seguir al equipo, aunque en realidad no se está obligado a hacerlo dado que disponer de carnet implica entrar al estadio sin pasar por taquilla y no un juramento de lealtad a la entidad. Los socios, salvo excepciones, coinciden ser también aficionados del club (independientemente de que puedan serlo también de otros clubes en primera o segunda opción), y aunque haya quienes se abonen especialmente por motivos de ahorro económico más que sentimentales hacia el club, lo cierto es que en la inmensa mayoría de casos ser socio y disponer del carnet del club constituye un signo distintivo de pertenencia con el que su propietario puede demostrar su apego al club y desde cuándo se produce. No es lo mismo serlo desde hace cuatro o cinco años, que el equipo juega en Primera, que serlo desde hace veinte o treinta, que se debatía en Segunda y Tercera División. De ese modo escuchamos:

La mayoría de la gente que acude al estadio llevan seis años yendo al fútbol, quien critique al Granada que me enseñe el carnet de hace veinte años cuando estábamos a punto de desaparecer (Enrique II, 53 años, 23/05/2016).

La condición de hincha (del Granada en este caso) constituye un paso más dentro de la multiplicidad de pasos, de cambios o consecución de nuevos estatus, que se dan en la sociedad moderna avanzada. Asimismo constituye un ejemplo más de la indeterminación de las fases de transición que, además de darse en los ciclos vitales, también se aprecia en otros rituales propios de nuestro tiempo (Pavón 2007: 311-387).

Si bien entre los seguidores o hinchas en general resultaría difícil identificar momentos puntuales como rituales de paso o de iniciación, y más aún un periodo liminal o liminar (Van Gennep 2008 [1960]; Turner 1988) en donde el protagonista se desprende de un estatus para adquirir otro, existe una categoría de ellos en donde tales momentos son más reconocibles: los hinchas ultras. Grupos de aficionados distinguibles del resto por el lugar que ocupan en las gradas, por cómo visten y por cómo se comportan en el estadio. Los Malayerba colocados todos juntos en la parte baja del Fon- 
do Sur, cerca de la zona de preferencia, visten con algún atuendo blanco (sudadera o camiseta), su logo es un Bull Dog con una cruz roja y tienen por líder a Marcos, seguidor acérrimo del Granada, con una personalidad muy especial y famoso por difundir mensajes de animación por las redes sociales, peña que no cesa de animar con canticos a su equipo; al igual que hace la Sección Kolokón, situados próximos a ellos vistiendo con camisetas o sudaderas negras, con un aspecto algo más intimidador ya que suelen llevar gafas de sol y la capucha sobre la cabeza. En las redes sociales también ocultan los rostros y para ser integrante del grupo exigen algunos requisitos estrictos: viajar con el grupo siempre que se organice una salida, acudir a las reuniones o seguir las iniciativas del speaker dentro del estadio. Aficionados que poseen un doble estatus en el estadio: seguidores del Granada C.F. y miembros de una peña especial de incondicionales; aficionados que distinguen de manera imprecisa cómo y desde cuándo se hicieron hinchas del Granada, pero que recuerdan cómo y en qué momento empezaron a formar parte de la peña que los agrupa, momento ese que para quienes lo viven por primera vez (ocupar el lugar reservado para el grupo, llevar el atuendo identificativo, sumar sus voces en los canticos, bailar el pogo o sincronizarse todos juntos cogidos lateralmente de los hombros) posee toda la fuerza psicológica y social de un ritual de paso con el que sentirse integrado en un nuevo colectivo que los acoge con agrado. Es en estos grupos donde pensamos que aflora en mayor grado la "communitas" (Turner 1988), el sentimiento de solidaridad suscitado por la proximidad de los símbolos propios que la hacen posible; aunque "la comunión entre quienes usualmente se encuentran separados estructuralmente por diferencias de rol y status" (Turner en Villena 2003: 30) alcanza a todos los seguidores distribuidos por el estadio.

También los rituales propiciatorios encuentran su espacio en el estadio. Dentro del terreno de juego no resulta raro observar jugadores que se persignan dos o tres veces, que se agachan a tocar el césped justo al entrar al campo, que miran al cielo señalándolo con el dedo dirigiéndole unas palabras; o al equipo al completo en el vestuario o en el campo antes de comenzar, formando piña y gritando todos a una su nombre, o cualquier otro gesto individual o colectivo que se tenga por costumbre, con el que sentirse más seguros, ganar confianza o pedir que la suerte les acompañe ese día. Así mismo, cuando uno se da por satisfecho al haber logrado un gol o ganado el partido, al igual que se hacen gestos simulando mecer un bebé, chuparse el dedo a modo de biberón, o señalar a alguien en señal de dedicatoria, hay quienes tienen por costumbre mirar de nuevo arriba señalando con el dedo como muestra de agradecimiento o de estar en deuda con la divinidad de la que se siente acompañado y beneficiado, cuando no es por dedicárselo a algún pariente o amigo fallecido. La creencia en la causa-efecto que tienen estos gestos con el deseo asociado a ellos es frecuente encontrarlo en jugadores y técnicos. El Arabi besa el césped en honor a Alá; Rochina suele entrar al campo saltando dos veces sobre su pierna izquierda; Peñaranda se arrodilla mirando al cielo cuando anota un gol; Sandoval se persignaba hasta tres veces cuando el equipo marcaba un gol, del mismo modo que Sergio Ramos (del Real Madrid) cuando visitó Los Cármenes el 25/08/2013.

$\mathrm{Al}$ igual que ocurre en el terreno de juego por parte de jugadores o entrenadores, se da en las gradas o fuera de ellas por parte del público. Realizar gestos o pronunciar palabras a modo de talismán para procurarle suerte al propio equipo es frecuen- 
te. Llevar siempre alguna prenda u objeto al estadio al entender que con ella se suele obtener un buen resultado, besar la camiseta o el escudo de su equipo para que su deseo de ganar se cumpla, o encomendarse a alguna entidad sagrada para lo mismo. El aficionado que disfrazado de Papa acude todos los días de partido a Los Cármenes, con un rosario y varias estampas de vírgenes se la pasa bendiciendo a la gente y es frecuente que, si hay un gol local, la gente le pida que no se vaya, por la buena suerte que trae. Este personaje, no obstante, en vez de ser considerado como ejemplo de alguna dimensión sagrada, es más bien ejemplo destacado de las licencias que la gente se permite en el estadio, dando rienda suelta a su imaginación para hacerse notar de alguna manera y lograr notoriedad. Los cánticos de animación al equipo están destinados a subir el ánimo, la moral de los jugadores para que se esfuercen y consigan triunfar; y algunos en especial por la letra y el tono en que se emiten persiguen a modo de mantra repetido insistentemente que surta el efecto deseado. Ocurre por ejemplo con aquél que dice: "Mete un gol, vamos Granada mete un gol".

Como podemos apreciar por todo lo dicho hasta aquí, en el Nuevo Estadio Los Cármenes la carga ritual es considerable, abundante y variada en sus formas de expresión y en las funciones que desempeñan. La ciudad de Granada cuenta con un estadio que para sus habitantes se convierte en un espacio ritual donde sublimar parte de sus anhelos, deseos y aspiraciones, así como para liberar o aliviar frustraciones. No obstante, por las características de este club de fútbol, históricamente más tiempo en Segunda y Tercera División que en Primera, los distintos tipos de rituales tienen para los granadinistas un nexo común que apunta a reproducir una idea o un ideal, el que dicta que una gran ciudad debe tener un gran estadio y un equipo en Primera División, en la "División de Honor" como se la conoce. Lo cual refuerza el axioma planteado por Hocart (1985: 31), al decir que: "el mito describe el ritual" en un papel orientador, mientras que "el ritual actualiza el mito", dándole vigencia.

Dentro de la antropología del deporte y del ritual (Blanchard y Chesca 1986; Foley 1990; Vaczi 2015), el estadio de fútbol ofrece un escenario privilegiado para la observación y análisis de comportamientos rituales que van mucho más allá de la catarsis colectiva y las manifestaciones violentas (Armstrong 1998; Garriga 2010 y 2015). Las identidades de género, especialmente masculino (Archetti 1998; Bromberger 2010; Llopis Goig 2010-2011); las identidades locales y nacionales (Fábregas 2001; Alabarces 2002; Bromberger 2007), las relaciones de poder entre clubes, la participación social y el intercambio emocional (Ramonet 1999; Llopis Goig 2006); la expresión de valores y creencias (Archetti 1985; Cachán y Fernández 1998; Bromberger 2000) derivadas del ambiente que genera este deporte se hallan presente en las gradas. Pero tal vez el principal aporte obedezca a que en este tipo de estadios se aprecia una dimensión más de lo sagrado en tiempos modernos, de aquello que resulta esencial para quienes regularmente acuden a ellos con pasión.

Sobre un aforo total de 23.156 asientos, el promedio de asistencia en la temporada 2014-2015 al Nuevo Estadio Los Cármenes fue de 16.515 (71,7 \%). Ningún otro acontecimiento en Granada y la provincia concentra la atención de tanta gente de manera regular. Tal circunstancia es motivo suficiente para que el espectáculo futbolístico en los estadios sea más tenido en cuenta desde las Ciencias Sociales y en especial desde la Antropología Social y Cultural, por la mirada cercana y detallista que puede ofrecer. Sin duda, al igual que otras manifestaciones deportivas, el fútbol como 
"espectáculo y acción", parafraseando a Cagigal (1981), es bueno para pensar en la persona y en la sociedad. Los rituales que desencadena condensan una serie de valores, normas y objetivos que tanto para las personas como para los colectivos, constituyen ejes vertebradores de la adaptación al momento histórico y al entorno social donde desarrollan sus vidas.

\section{IDENTIDAD Y ALTERIDAD}

Las creencias y los valores, los mitos y los ritos presentes en el estadio y por extensión en el fútbol, generan señas de identidad y de alteridad, marcas de distinción por las que unos se igualan y otros se diferencian. Olven y Damo (2001) ya señalaban el sistema de lealtades que en el fútbol funciona de manera comparable al que puede existir por una región o por un país. El éxito o fracaso del equipo hace vibrar a los aficionados de emoción o sufrir resignadamente. Y el hecho de que un hincha cambie de equipo es percibido por muchos como una traición. Incluso cuando son los jugadores quienes cambian al ser traspasados, como profesionales que son, se consideran traidores, según qué casos, cuando ellos solicitan o sugieren el traspaso.

Ser hincha del Granada, como de cualquier otro equipo, obedece a distintos motivos, aunque generalmente tiene que ver con la vinculación al territorio, como también apreciaba Giménez (en Ramírez Gallegos 2003: 112), ya que los denominados "hinchas de la globalización" (Cáceres 2011) lo son de los equipos más mediáticos o asociados a ciertos clichés históricos (Real Madrid, Barcelona, Atlético de Madrid, Athletic de Bilbao, Betis,...). Pero aunque el aficionado sepa cuál es su equipo preferido, el equipo con el que se emociona, que le produce alegría cuando gana y tristeza cuando pierde, le cuesta mucho verbalizar por qué, a qué se debe. Un aficionado no suele ser hincha del Granada por cómo se comporte la directiva del club, por las obras de caridad que pueda hacer, o la tendencia política del presidente; tampoco suele serlo por obligación, exceptuando los casos de aquellos/as que lo son o simulan serlo por no disgustar o llevar la contraria al papá o al marido; se es hincha por motivos fundamentalmente emotivos o sentimentales y la costumbre de serlo hace difícil la escapatoria. Aunque el círculo de seguidores puede ampliarse o reducirse de manera significativa en función de los resultados del equipo, no pasa desapercibido que 2011, año en que el Granada C.F. subió por última vez a Primera División sea una fecha emblemática, no solo por tal acontecimiento, sino por el resurgir de una hinchada más numerosa y entusiasmada, y por la creación de peñas autodenominadas ultras o de animación sin más, que con el transcurrir de los años fue en aumento.

Como ejemplo altamente significativo de hasta qué punto los seguidores del Granada se identifican con su equipo y lo sienten cerca, tenemos el caso de "Migue", joven de 19 años (en junio de 2016), invidente pero enormemente activo, que no por su discapacidad visual deja de practicar un buen número de deportes como el esquí, atletismo, ciclismo en tanden, etc., o ejercer de costalero en Semana Santa. Apasionado por el fútbol e hincha del equipo de su ciudad, va acompañado de su hermano regularmente a Los Cármenes y junto a su peña Malayerba es uno de los aficionados que más anima al equipo durante todo el partido. Como él mismo dice: «A mí me gusta que me animen y por tanto me gusta animar". Modelo indiscutible de supera- 
ción, hace valer como nadie la consigna granadinista de "lucha eterna". Su madre haciéndose eco de sus palabras dice: "No hay límites, el límite lo pones tu mismo". Los límites a los que se refiere no son solo físicos obviamente, dado que como dice Migue: "Hay colores que no se ven pero que sí se sienten", o como dice su padre: "No hay que tener ojos para ver, hay que tener corazón".

Los grupos de animación tienen un lema: "No trates de entenderlo... es un sentimiento". Y una frase muy escuchada es: "Si jugaras en el cielo, moriría para verte». Las personas fallecidas se dice que están "viéndote desde el cuarto anillo", en referencia a las gradas del estadio (que son tres). Y hay un cántico que dice: "De pequeño yo te empecé a seguir, poco a poco, me enamore de ti, cuando juegues, siempre estaré a tu lado, por eso no me falles, yo nunca te he fallado".

Factores emocionales a los que hay que sumar, no obstante, los ideales que el público proyecta en el club, o que el club proyecta en los aficionados, ideales que en muchos equipos guarda relación con el estilo tradicional de juego que desarrollan, como señalaba Bromberger (2007: 128), y que en otros se sostiene en alguna cualidad que se desea hacer valer como distintiva de la institución. En el caso del Granada la "lucha eterna", como aparece junto al escudo en su página web; el hecho o el deseo de "luchar para ganar", como se canta en el himno y se estampa en las camisetas de los jugadores, entendida como segunda piel; parece que es la principal consigna que instalada en el imaginario de la hinchada activa su sentimiento de pertenencia y la representación de una identidad compartida. Según los datos de la encuesta para el 80,5\% de los casos (91 personas) ser seguidor/a del Granada C.F. es un hecho importante para su identidad personal.

Emotivos son también los factores por los que un hincha del Granada siente especial aversión por ciertos clubes eventuales rivales del suyo. De manera puntual se puede sentir rechazo por el club que ha sido el último responsable en provocar el descalabro final del propio equipo, o que ha realizado declaraciones ofensivas; pero las plantillas cambian, también los presidentes, sin embargo la animadversión puede prolongarse durante años y convertirse en histórica. Caso del Elche o del Sevilla, por ejemplo, en relación con el Granada, que los malos modos de las aficiones en la temporada 2015-2016 se deben a lo ocurrido en temporadas precedentes. En el polo opuesto encontramos excelentes relaciones entre directivas y aficiones rivales, como ocurre con la del Real Madrid, el Atlético de Madrid, el Valencia, el Deportivo de la Coruña, o el Villarreal; que llegan incluso a actos protocolarios de hermanamiento entre clubes y gestos de buenos deseos entre las aficiones, como ocurrió en la temporada 2013-2014 entre la del Granada y la del Málaga. Los antagonismos y las adhesiones de ese tipo son, no obstante, circunstanciales y no permanentes.

El fútbol desata emociones y es terreno abonado para construir relaciones de semejanza y de diferencia, para aproximarse a unos y distinguirse de otros, para la afirmación de identidades y alteridades colectivas. Salvando las distancias, como expresa Fábregas (2006: 158-160) con el caso chiapaneco, provoca integración social a costa de su fragmentación. Entre los aficionados del Granada C.F. apreciamos identidades territoriales y locales ligadas al club e identidades de rol ligadas con determinados jugadores por las cualidades que demuestran tener, al igual que apreciaba Villena (2003: 26) en los casos sudamericanos por él estudiados. Identidades que, de acuerdo con este autor, también consideramos que en algunos casos son precarias, múltiples y 
susceptibles de transformación (2003: 29), pero que en otros muchos son sólidas y resistentes al cambio. Si bien unos aficionados se vuelcan en mayor o menor medida con el equipo en función de los resultados, otros mantienen una actitud estoica y se muestran incondicionales en el apoyo a los suyos pase lo que pase.

En otro orden, especialmente importante resulta destacar la asociación de ideas que se da entre el himno y los cánticos que se producen en el estadio con lo que pretenden transmitir. En el himno se evoca el espíritu de lucha que hay que mantener para ganar: "Hay que luchar para ganar, con fuerza y con valor, hasta que el estadio tiemble, hasta que la gente grite, ¡GOL, GOL!». O se alude a los sentimientos, a esa fuerza oculta cuya atracción por el club y la ciudad los llena de gozo: "Granada, tu embrujo me enamora, tu gente y tu pasión, me llena el corazón".

Este himno emotivo entonado al unísono por miles de espectadores levanta el ánimo de todos quienes participan de él, no solo de los jugadores, y refuerza la seña de identidad y la sensación de estar juntos. También se suele cantar al saltar los equipos al césped, con alguna estrofa a capela, para darle más emotividad. Pero además del himno reproducido en momentos puntuales, lo que se pone en escena de manera más frecuente son los numerosos cánticos que de forma espontánea, aunque con letra fija, tienen lugar, generalmente dirigidos o bajo la iniciativa de los grupos de animación y/o grupos ultras. Cánticos muy diversos que por lo común invocan su nombre, o el esperado gol, expresan el apoyo al equipo y le imprimen ánimo y energía. Como muestra de ello reproducimos algunos fragmentos:

A por ellos oe. A por ellos oe.

Vamos mi Granada. Vamos campeónnnn. Lo lo lo lo loooooooo.

Hasta el final. Vamos Graná.

Vamos mi Granada. Vamos. Con más huevos. Hoy ganamos.

Esta es la afición. Del equipo campeón.

Pedazo de cojones. Tiene mi Grana.

Vamos juntos a animar. Animando sin parar. La victoria llegará.

Yo levanto la cabeza orgulloso. Y le digo del Granada hasta morir.

Es de Primera. Granada es de Primera.

Estos cánticos de aficionados también hablan de sí mismos, del grupo que lo entona, todos a una, con la intención (entendemos) de mostrar públicamente su actitud, de hacerse notar y reconocer ante todos. De este modo oímos estrofas como:

Échale huevos. Ponle más corazón. Como ponemos los ultras del kolokon. Lo damos todo. Por defender esta camiseta.

Amaras siempre a tus colores. Y por eso la sangre es Graná. Y si alguien intenta ofendernos. Esta peña con ella acabará.

Yo te vengo aquí animar, la la la la. Aunque sea desde el cielo, lo lo lo. Pero nunca olvidaré, lo lo lo lo. Granada como te quiero, lo lo lo.

Pasa el tiempo pasa la gente. Jugadores y presidentes. Y nosotros aquí presentes. Animando hasta la muerte.

Y no faltan cánticos ofensivos con cierta intencionalidad, aunque tan solo sea de desahogo personal y colectivo, que provoca la adhesión de unos y la indignación de otros.

Esto es Graná y aquí hay que mamar.

Si todavía se mueve, vuélvelo a pisar. 
La identidad local y territorial de los hinchas del Granada se ve fortalecida por la continua referencia a la lucha, unida si cabe a los huevos que como atributo masculino han de estar presentes siempre para no rendirse jamás, atributos de los que hablan y corean igualmente las mujeres de la hinchada ${ }^{4}$. Identidad por tanto con un equipo, con unos colores ${ }^{5}$ en los que se sienten representadas las gentes de un lugar que así lo sienten, y en la que reconocemos un signo distintivo sobresaliente: "el aguante». Aguante no asociado al sentido ofrecido por Alabarces, Garriga y Moreira (2008), ligado con la violencia, con el desafío entre bandas para ver quién da más duro y quién es el que hace retirar al otro del sitio; sino ligado al sentido de ver o exigir al propio equipo que sea un modelo de resistencia ante la adversidad y, como ya acostumbran, aguantar a encajar malos resultados sin llegar a caer en la resignación. Mientras que el equipo debe aprender de los errores cometidos, modificar sistemas de juego y seguir luchando, los seguidores han de renovar el ánimo y la ilusión. La cultura del aguante se convierte así en un mecanismo adaptativo para encajar decepciones, para estar satisfecho y orgulloso de ser hincha de un equipo cuyo nivel de aspiraciones suele estar por encima del nivel de posibilidades reales para conseguirlas.

Tal circunstancia marca diferencias entre aficiones, la incertidumbre por el resultado siempre o casi siempre está presente, pero unas están más acostumbradas que otras a soportar frustraciones por las derrotas, a desarrollar la fe más o menos inquebrantable en el equipo. La del Granada C.F., según apreciamos en numerosas conversaciones, manifiesta estar acostumbrada a ello, su reciente himno resalta el empuje de la hinchada y termina diciendo que "somos el número doce de tu alineación"; pero como ya señalamos antes no toda por igual. La alteridad también se encuentra dentro de la misma afición como ella misma reconoce al reprocharse las actitudes pasivas de unos a otros:

Desde el Fondo Sur recriminamos la actitud de la Tribuna, al no animar en ningún momento o escucharse murmullo cuando encajamos un gol, [...] desde la grada de animación estamos continuamente animando al equipo y no nos gustan los comepipas (Antonio, 26 años, 17/05/2016).

Los signos de distinción se hallan también muy presentes entre quienes se consideran animadores incondicionales. Los ultras de Malayerba visten distintos que los ultras de Sección Kolokón, cada cual tiene un espacio reservado en el estadio y se alternan en los cánticos de apoyo al equipo, pero no se mezclan. La Asociación G19 Peñas del Granada C.F. agrupa en la actualidad a 37 peñas repartidas por toda la provincia de Granada, Barcelona, Sevilla, Canarias, así como en Irlanda, Francia y Argentina.

${ }^{4}$ El lenguaje obsceno y ofensivo que se produce en las gradas del estadio constituye, como señala Garriga (2015), una nota más de la alteridad de los hinchas de fútbol con respecto al resto de la sociedad, al normalizar y otorgarle positividad a las prácticas que los otros negativizan.

${ }^{5}$ Las metáforas cromáticas son utilizadas como marca de identidad: "el coliseo rojiblanco" (estadio del GCF); "los rojiblancos" (granadinistas). Términos que a veces puede generar confusión y controversia, cuando son asignados a dos o más equipos y les toca jugar juntos; circunstancia que en el caso del Granada puede suceder cuando compite con el Atlético de Madrid, también "rojiblancos". Colores por el que se distinguen las camisetas de los equipos y con los que se identifican los aficionados, que dicen sentir o querer a su equipo por los colores: "hay que sentir y querer los colores del Granada”. 
Todas ellas tienen mucho en común pero también rasgos distintivos de historia y procedencia que le dan singularidad propia. Lo cual nos hace entender que los procesos de identidad y alteridad en estos casos, como en otros muchos, lejos de ser antagónicos son complementarios.

\section{CONCLUSIONES}

Las metáforas, el uso de términos y frases en sentido figurado es muy propio del espectáculo futbolístico. Como ocurre en cualquier estadio, los aficionados del Granada reproducen el lenguaje cargado de connotaciones bélicas que es habitual, con analogías al ámbito de lo sagrado. Todo ello, unido a la exaltación de jugadores como héroes o ídolos y a sus actuaciones como hazañas o verdaderas proezas, genera un universo simbólico y mitológico condicionado por lo que los propios términos insinúan, en donde la realidad se idealiza, se interpreta y entiende bajo el filtro de emociones y esperanzas.

Desde el punto de vista simbólico cada nueva temporada constituye un largo proceso ritual, y los aficionados en los estadios, partido tras partido, repiten el papel que les toca desempeñar. Los estadios de fútbol son espacios cargados de simbolismo, de acontecimientos y situaciones vividos repletos de emoción, que exige un mínimo de empatía por parte de quienes se acerquen a él para comprender lo que allí ocurre. Lo que a unos, visto desde fuera, les puede parecer una imagen exótica y absurda, ver disfrazados a muchos entusiastas vitoreando y dando saltos cuando reciben al autobús de jugadores a la entrada del estadio; o una panda de energúmenos desgañitándose con cánticos absurdos cuando animan a su equipo dentro del estadio; a otros, visto desde dentro, les resulta difícil de expresar con palabras las emociones que experimentan porque es indescriptible lo que sienten. Difícil resulta explicar emociones e igualmente resulta entenderlas si no es también desde la emoción, colocándose en la piel del otro.

Sin necesidad siquiera de entrar en el estadio, observar desde fuera lo que ocurre en sus aledaños un día de partido es suficiente para tener una idea de la dimensión social y el potencial simbólico que entraña: miles de personas movilizadas llenan el espacio de colorido, enarbolan banderas, entonan cánticos, brindan con cerveza en los bares, se apelotonan en las entradas al recinto; en las miradas de la gente se intuye ilusión y los rostros muestran por lo general expresiones alegres; las gentes han transformado el lugar en un espacio y en un tiempo festivo por unas horas. Los hinchas de ambos equipos, ya ubicados dentro del estadio, más que como grupos antagónicos porque cada cual anime a los suyos y a veces ridiculicen u ofendan a los otros, ejercen papeles complementarios, porque ser del Granada C.F. no tendría sentido si no existieran a su vez los del Villarreal, el Elche o Las Palmas; por pocos seguidores que hayan ido en esa ocasión y ocupen un espacio residual en una esquina del recinto, dan testimonio del otro con quién medirse, compararse o competir. Los extremos una vez más se tocan y las hinchadas aparentemente opuestas resultan ser complementarias.

Coincidiendo con Ramonet (1999) y Fábregas (2001), el fútbol llega a desempeñar en nuestros días los papeles que tradicionalmente cumplía la religión o la política; y 
dejando a un lado las interpretaciones simplistas que lo señalan como la adormidera o el opio del pueblo, constituye un fenómeno susceptible de ser analizado para una mejor comprensión de la sociedad del presente, inmersa en un sistema capitalista y envuelta en un permanente debate entre lo global y lo local.

Un fenómeno tan complejo como el fútbol, universal pero con infinidad de perfiles, aristas y flecos, lo hemos acotado en lo que entendemos máximo lugar de celebración: el estadio, un solo estadio, el del Granada C.F., aunque éste pueda ejemplificar lo que ocurre en otros muchos. Estadio que reúne gran cantidad de aficionados y sublima las emociones que estos portan por separado. Lugar en donde se percibe un ejemplo más de "comunidad imaginada" (Anderson 1993 [1983]), de colectivo vinculado entre sí por la afinidad con un club, con un club que, independientemente de las vinculaciones políticas o nacionalistas que aparezcan en otros casos, como todos los clubes de estas características son algo más que clubes deportivos, en la medida que desarrollan estímulos que facilitan la identificación de las personas y con ello la integración de unos y la distinción de otros. El conocimiento de ese algo más, en el que aquí contribuimos con esta aportación, debería ser bienvenido en futuras investigaciones desde las Ciencias Sociales por las implicaciones y consecuencias que entraña, implicaciones y consecuencias condensadas en el estadio, en los estadios, pero que trascienden a ellos para alcanzar esferas cada vez más amplias y de difícil delimitación.

\section{BIBLIOGRAFÍA CITADA}

Alabarces, Pablo. 2002. Fútbol y Patria. El fútbol y las narrativas nacionales en la Argentina. Buenos Aires: Prometeo.

Alabarces, Pablo, José Garriga y M. ${ }^{a}$ Verónica Moreira. 2008. "El "aguante” y las hinchadas argentinas: una relación violenta". Horizontes Antropológicos 30: 113-136.

Anderson, Benedict. 1993 [1983]. Comunidades imaginadas. Reflexiones sobre el origen y la difusión del nacionalismo. México: Fondo de Cultura Económica.

Archetti, Eduardo. 1985. Fútbol y ethos. Buenos Aires: FLACSO.

Archetti, Eduardo. 1998. "El potrero y el pibe. Territorio y pertenencia en el imaginario del fútbol argentino". Nueva Sociedad 154: 101-119.

Armstrong, Gary. 1998. Football Hooligans: Knowing the Score (Explorations in Anthropology). Londres: Berg.

Blanchard, Kendall y Alyce Chesca. 1986. Antropología del deporte. Barcelona: Bellaterra.

Bourdieu, Pierre. 1991 [1980]. El sentido práctico. Madrid: Taurus.

Bromberger, Christian. 1989. "Le stade de football: une carte de la ville en réduction". Mappe Monde 89(2): 37-40.

Bromberger, Christian. 2000. "El fútbol como visión del mundo y como ritual”, en M. a Ángeles Roque (ed.), Nueva Antropología de las sociedades mediterráneas: 253-274. Barcelona: ICARIA/Institut Catalá de la Mediterrania.

Bromberger, Christian. 2007. "Cultures and identities in Europe through the looking glass of football", en Marion Demossier (ed.), The European puzzle. The Political Structuring of Cultural Identities at a Time of Transition: 119-140. Nueva York/Oxford: Berghahn Books.

Bromberger, Christian. 2010. "Sport, football and masculine identity", en Sybille Frank y Silke Steets (eds.), Stadium worlds: Football, Space and the Built Environment: 181-194. Londres: Routledge.

Bromberger, Christian. 2011. "Football, la bagatelle la plus sérieuse du monde". Conferencia pronunciada en Vaison-la-Romaine, el 18 mayo de 2011. 
Cachán, Roberto y Oscar Fernández. 1998. "Deporte o Religión: Un análisis antropológico del fútbol como fenómeno religioso". Apunts 52: 10-14.

Cáceres, Juan S. 2011. Las metáforas bélicas del fútbol: un fenómeno cultural y discursivo. Tesis de Grado en Comunicación Social. Bogotá: Pontificia Universidad Javeriana Facultad de Periodismo y Comunicación Social.

Cagigal, José María. 1981. Deporte: Espectáculo y acción. Barcelona: Salvat Editores.

Dávila, Andrés y Catalina Londoño. 2003. "La nación bajo un uniforme. Fútbol e identidad nacional en Colombia, 1985-2000", en Pablo Alabarces (comp.), Futbologias. Fútbol, identidad y violencia en América Latina: 123-144. Buenos Aires: Consejo Latinoamericano de Ciencias Sociales.

Fábregas, Andrés. 2001. Lo sagrado del Rebaño. El fútbol como integrador de identidades. Guadalajara: Colegio de Jalisco.

Fábregas, Andrés. 2006. "El fútbol en Chiapas (México): ¿un símbolo de identidad?». Revista de Dialectologia y Tradiciones Populares 61(2): 145-161.

Ferreiro, Juan Pablo. 2003. "Ni la muerte nos va a separar, desde el cielo te voy a alentar". Apuntes sobre identidad y fútbol en Jujuy", en Pablo Alabarces (ed.), Futbologias. Fútbol, identidad y violencia en América Latina: 57-74. Buenos Aires: Consejo Latinoamericano de Ciencias Sociales.

Foley, Douglas E. 1990. "The Great American Football Ritual: Reproducing Class, Race, and Gender Inequality". Sociology of Sport Journal 7: 111-135.

Foucault, Michel. 1976. Vigilar y castigar. Nacimiento de la prisión. Buenos Aires: Siglo XXI Editores.

Galeano, Eduardo. 1995. El futbol a sol y sombra. Bogotá: Tercer Mundo Editores.

Garriga, José. 2010. Nosotros nos peleamos. Violencia e identidad en una hinchada de fútbol. Buenos Aires: Prometeo.

Garriga, José (comp.). 2015. Violencia en el fútbol: investigaciones sociales y fracasos políticos. Buenos Aires: Ediciones Godot.

Geertz, Clifford. 1987 [1973]. La interpretación de las culturas. Barcelona: Gedisa.

Giménez, Gilberto. 1999. "Materiales para una teoría de las identidades sociales", en José Manuel Valenzuela (ed.), Decadencia y auge de las identidades. México: Colegio de la Frontera Norte/ Plaza y Janés.

Girard, René. 1985. La violencia y lo sagrado. Barcelona: Anagrama.

González Ponce de León, Miguel Ángel. 2009. "Estructura Social y sistema simbólico en el ritual de los grupos de animación de un equipo de fútbol. El surgimiento de la ultra 1901 como movimiento contestatario al orden social hegemónico". Razón y Palabra 69: 1-15.

Guerrero, Patricio. 2002. La Cultura. Estrategias conceptuales para entender la identidad, la diversidad, la alteridad y la diferencia. Quito: Ediciones Abya-Yala.

Harris, Marvin. 1984. Introducción a la antropología general. Madrid: Alianza Universidad.

Hocart, Arthur. 1985. Mito, ritual y costumbre. Ensayos heterodoxos. Madrid: Siglo XXI.

Ibañez, Tomás. 1988. Ideologias de la vida cotidiana. Barcelona: Sendai.

Lakoff, George y Mark Johnson. 1998. Metáforas de la vida cotidiana. Madrid: Cátedra.

Llopis Goig, Ramón. 2006. «El fútbol como ritual festivo. Un análisis referido a la sociedad española". Anduli. Revista Andaluza de Ciencias Sociales 6: 115-132.

Llopis Goig, Ramón. 2010-2011. "Identitats de gènere i esport. Masculinitats inductores i resistències a la masculinitat hegemònica al futbol español.. Anuari de Psicologia de la Societat Valenciana de Psicologia 13(1-2): 93-108.

Mora, Martín. 2002. "La teoría de las representaciones sociales de Serge Moscovici". Athenea Digital 2: [s. p.]. doi: $10.5565 / \mathrm{rev} /$ athenead/v1n2.55.

Moscovici, Serge. 1979 [1961]. El psicoanálisis, su imagen y su público. Buenos Aires: Huemul.

Olven, Ruben y Arlei Damo. 2001. Fútbol y Cultura. Bogotá: Grupo Editorial Norma.

Pavón, José Miguel. 2007. Los ritos de paso al principio del tercer milenio. Madrid: Noesis.

Ramírez Gallegos, Jacques Paul. 2003. "Fútbol e identidad regional en Ecuador", en Pablo Alabarces (ed.), Futbologías. Fútbol, identidad y violencia en América Latina: 101-122. Buenos Aires: Consejo Latinoamericano de Ciencias Sociales.

Ramonet, Ignacio. 1999. "Un hecho social total", en Santiago Segurola (ed.), Fútbol y pasiones políticas: 11-19. Barcelona: Debate. 
Sperber, Dan. 1988. El simbolismo en general. Barcelona: Anthropos.

Turner, Víctor. 1988. El proceso ritual. Madrid: Taurus.

Vaczi, Mariann. 2015. Soccer, Culture and Society in Spain: An Ethnography of Basque Fandom. Londres/Nueva York: Routledge.

Van Gennep, Arnold. 2008 [1960]. Los rituales de paso. Madrid: Alianza Editorial.

Vázquez Montalbán, Manuel. 2005. Fútbol. Una religión en busca de un Dios. Barcelona: Debate. Verdú, Vicente. 1980. El fútbol: mitos, ritos y símbolos. Madrid: Alianza Editorial.

Villena, Sergio. 2003. "Gol-balización, identidades nacionales y fútbol", en Pablo Alabarces (ed.), Futbologias. Fútbol, identidad y violencia en América Latina: 257-269. Buenos Aires: Consejo Latinoamericano de Ciencias Sociales.

Fecha de recepción: 21 diciembre de 2016 Fecha de aceptación: 24 de junio de 2017 